\title{
CORTICOSTEROIDS - (UN)PREDICTABLE INDUCERS OF PSYCHIATRIC DISORDERS.
}

\author{
Tatyana Telbizova, Mariana Arnaoudova \\ Department of psychiatry and medical psychology, Medical University-Varna, \\ MHAT “St. Marina”-Varna, Bulgaria.
}

\begin{abstract}
Synthetic corticosteroids are a widely used and highly effective group of drugs for the treatment of a number of diseases. They have the potential to induce a broad spectrum of psychotic disorders that are often misdiagnosed, underestimated and unpredictable.

Objective: The aim of the present article is to report two cases of corticosteroid-related psychotic disorders.

The first case was a patient who has undergone allogeneic bone marrow transplantation, followed by an oral administration of prednisolone with an initial daily dose of $100 \mathrm{mg}$, subsequently reduced by $10 \mathrm{mg}$ per week. Upon reaching a dose of $50 \mathrm{mg}$ daily, the patient suddenly became psychomotor agitated, in an elevated mood, with ecstatic and megalomaniac experiences. Prednisolone treatment was discontinued, and olanzapine was initiated at doses of $10 \mathrm{mg} /$ day and diazepam at $10 \mathrm{mg} / \mathrm{night}$. Within 5 days, the described psychopathological symptoms were de-actualized, and the antipsychotic treatment was discontinued.

The second case was a patient who was on a supportive treatment of four accompanying autoimmune diseases with methylprednisolone $4 \mathrm{mg} /$ day and developed anxiety-depressive symptoms. Administration of Milnacipran at a maintenance dose of $100 \mathrm{mg}$ /day led to significant reductions in depression and anxiety.

Conclusion: Corticosteroids have a high potential to induce a wide range of mental disorders. Clinicians and patients should be aware of these adverse effects. Inability to stop the corticosteroid treatment in many cases requires the use of psychotropic medications. Both drug interactions and the potential side effects need to be taken into consideration.
\end{abstract} order

Keywords: corticosteroid, psychosis, psychotic dis-

\section{INTRODUCTION:}

Synthetic corticosteroids are a widely used and highly effective group of drugs for the treatment of a number of diseases with immunological, neoplastic and inflammatory diathesis such as rheumatoid arthritis, systemic lupus erythematosus, systemic vasculitis, asthma and chronic obstructive pulmonary disease, neoplastic processes [1], acute and chronic pain [2], for medical management of brain tumors [3].

Side effects of corticosteroids such as obesity, infections, diabetes, cardiovascular diseases, osteoporosis, peptic ulcers, ophthalmological complications (glaucoma and cataracts), skin atrophy, etc. are well known [4]. They have the potential to induce a wide range of mental disorders that are often misdiagnosed, underestimated and unpredictable [5]. The mechanisms of their occurrence have not been sufficiently studied [6]. This requires careful assessment of the risk factors and use of safe doses of this group of medications.

\section{Mechanism of action:}

Endogenous glucocorticoids are steroid hormones released by the adrenal cortex, and their plasma concentration is under the control of the hypothalamic-pituitaryadrenal axis. They play a major role in modulating homeostasis and coordinating adaptive responses associated with acute and chronic stress [7].

Their effects on the CNS are associated with controlling hunger sensation and circadian rhythm. They also influence the processes of learning and memory. Steroid receptors are located in the prefrontal cortex, hippocampus and basolateral side of the amygdala. Their role is related to the regulation of serotonin and dopamine neurotransmission, and respectively to emotions, memory and behaviour. The negative feedback provides activation of the hypothalamic-pituitary-adrenal axis with subsequent induction of cortisol overproduction. There is a relationship between high levels of endogenous cortisol and hippocampal atrophy leading to cognitive dysfunctions [8].

Mechanisms for the occurrence of symptoms of depression, mania, and psychoses in the administration of synthetic corticosteroids have not yet been adequately studied. The relationship between impaired cortisol secretion and depression has been already demonstrated in the 1970s by the dexamethasone suppression test [9]. It has been established that patients with major depressive episodes have elevated inflammatory biomarkers in peripheral blood, including cytokines, for which production of glucocorticosteroids is responsible. Activated inflammatory pathways in the brain contribute to impaired gluta- 
mate release, oxidative stress and glial cell loss [10]. Administration of prednisone is associated with decreased levels of corticotropin, norepinephrine, beta-endorphin and beta-lipotropin in cerebrospinal fluid [6].

Therefore, cortisol inhibits neurogenesis, induces loss of neuroplasticity and reduces hippocampal volume. Thus it serves as a mediator of cognitive symptoms in depression [11].

Various psychiatric disorders may be part of the clinical picture of Cushing's disease (hypercortisolemia) and Addison's disease (hypocortisolemia). They belong to the group of organic and symptomatic psychiatric disorders in endocrine diseases. Usually, the psychopathology manifests with the clinical picture of an endocrine psycho-syndrome, which does not differ from Bleuler's local (focal) psycho-syndrome with changes of urges, affinities and moods [12]. Cushing's disease is associated with generalized anxiety, panic disorders, depression, euphoria, hypomania, mania and psychosis, while Addison's disease can lead to fatigue, lack of energy, decreased appetite, and depressed mood - symptoms of depression [13].

\section{Psychiatric disorders and corticosteroids:}

Psychiatric disorders observed in corticosteroid treatment include: mood disorders (depression, hypomania, mania, mixed states) $[14,15]$, incl. suicidal behavior in the context of affective syndromes, anxiety disorders, incl. panic disorder $[15,16]$, delirium [14], insomnia [16, $15,17]$, catatonia [17], cognitive disorders - isolated cognitive disorders and reversible corticosteroid-induced dementia [18], agitation [17, 18], euphoria [19].

Psychiatric symptoms are dose-dependent and usually begin during the first few weeks of the treatment [20]. Severe mental disorders were observed in $5 \%$ of those treated with corticosteroids [21, 22]. Nearly $28 \%$ of the patients had mild and moderate disorders [22]. Clinical symptoms can develop at any time: during the drug administration, as well as after completion or discontinuation of the treatment [17]. In most cases (86\%) symptoms occurred during the first 5 days of the treatment. After discontinuation of the corticosteroid therapy, depression symptoms may persist for 4 weeks, mania symptoms up to 3 weeks, and delirium symptoms may completely resolve within a few days. Approximately half of the patients with corticosteroid-induced psychosis improved within 4 days and the remaining half - within 2 weeks [21, 23]. It has been shown that discontinuation of long-term glucocorticoid therapy (conducted for at least three months or more) is associated with an increased risk of depression and delirium [24].

Patients with corticosteroid-induced psychiatric disorders may be subject to forensic psychiatric expertise. Turner (1987) described a case of a patient with ulcerative colitis, treated with prednisolone at doses between 30-60 mg/day. In the hypomanic state, the patient committed theft, was subjected to criminal liability and found guilty. This example clearly emphasizes the need for patients taking corticosteroids to be alerted about possible changes in urges, motivation and behaviour, and for a realistic assessment of various situations, respectively [25].

\section{Risk factors:}

Risk factors for the development of corticosteroidinduced and psychotic disorders have not been fully understood.

\section{Dosage}

As early as 1972, data from the Boston Collaborative Surveillance Program have been published to prove the relationship between the dose of administered corticosteroids and the incidence of psychiatric symptoms and syndromes. Psychiatric symptoms and syndromes rarely manifest at doses of less than $40 \mathrm{mg} /$ day of prednisolone (1.3\%). When the dose increased up to $41-80 \mathrm{mg} / \mathrm{d}$, the incidence increased by $4.6 \%$, and at $>80 \mathrm{mg} / \mathrm{d}$ by $18.4 \%$ [20]. Therefore, high doses of corticosteroids are a predisposition for the manifestation of psychiatric side effects. There is no data on whether high doses affect the occurrence of a particular psychiatric disorder.

In a literature review, Ling et al. (1981) found that there was no relationship between dose and duration of corticosteroid treatment on the severity of symptoms and their onset. In addition, corticosteroid-induced psychiatric disorders are reversible and dose reduction and/or discontinuation of treatment results in de-actualization of the leading symptoms and syndromes [26].

\section{Treatment duration}

The most common psychiatric disorders during short-term corticosteroid therapy are euphoria and hypomania. Long-term treatment with corticosteroids is associated with the development of depression, rather than mania symptoms $[21,22,27]$.

\section{Gender}

Whether gender plays a role in the manifestation of corticosteroid-induced psychiatric side effects is still a disputable issue. According to Ling, the female gender is a predisposition for psychiatric symptoms [26].

Age

Adults over 65 years of age are characterized by: 1) polymorbidity - somatic and psychiatric; 2) dominating vascular, organic and neurodegenerative disorders; 3 ) changes in pharmacokinetics and pharmacodynamics $[11,18]$. These characteristics are at the root of their vulnerability to the manifestation of psychiatric side effects of corticosteroid therapy. Especially high is the risk of developing symptoms of delirium. The risk increases in long-acting glucocorticoids treatment [24]. Other studies have demonstrated that symptoms of hyperactivity, irritability, insomnia, and attention and memory deficit have been observed in $73 \%$ of the pediatric population, treated with corticosteroids. Children under 10 years of age and those receiving high doses of corticosteroids are particularly vulnerable. [28]. 


\section{Route of administration}

Corticosteroids have the potential to induce psychiatric disorders not only when administered orally. Data has been accumulated that they can also be observed in both epidural and intra-articular administration as part of pain management interventional procedures [29]. Psychotic episodes have been described both in a single (80 mg methylprednisolone) and repeated intra-articular (40 mg methylprednisolone) administration [30]. Most of the described cases with psychotic episodes due to intra-articular corticosteroids are in patients over 65 years of age. This supports the data that adults are a high-risk patient group, predisposed to psychiatric side effects [29,30].

\section{Previous psychiatric disorders}

Patients who had previous psychiatric disorders, as well as corticosteroid-induced psychiatric disorders are not associated with a higher risk of repeated clinical exposure to psychiatric side effects in a subsequent course of corticosteroid therapy [26]

\section{Other risk factors}

Hypoalbuminemia, as well as drug interactions related to cytochrome P450 enzyme (CYP) 3A4 inhibition, have been described as potential risk factors.

Liu and Vasudev (2014) report a case of mania induced by clarithromycin in a geriatric patient on a low dose of prednisone of $5 \mathrm{mg}$ a day. Withdrawal of clarithromycin, a cytochrome P450 enzyme (CYP) 3A4 inhibitor, from the therapeutic regimen and the addition of olanzapine, led to de-actualization of psychotic symptoms over the next 8 days [31]. Powerful CYP 3A4 inhibitors are: ketoconazole, clarithromycin, erythromycin, verapamil, diltiazem, nefazodone and fluvoxamine [32].

Chau and Mok (2003) recorded psychotic symptoms in $5 \%$ of the 92 systemic lupus erythematosus patients treated with corticosteroids. They found that hypoalbuminemia is a factor that can predict the manifestation of psychosis [33].

Among the most common corticosteroid-induced psychiatric disorders are euphoria, depression and psychotic episodes [26]. In ICD-10, the toxic effects of nonpsychotropic drugs are classified under the F06 heading Other mental disorders due to brain damage and dysfunction and to physical disease. This category comprises also all diseases, including endocrine disorders (hypocortisolism and hypercortisolism), associated with different psychiatric symptoms [34].

\section{TREATMENT:}

Generally, psychiatric disorders associated with corticosteroid treatment are de-actualized after their removal from the therapeutic regimen. Some cases (about 20\%) require treatment of depression, mania or psychosis [20]. The basic rule is to reduce the dose and reach the lowest effective dosage. Treatment is conducted with drugs approved for the treatment of the corresponding psychiatric disorders [35]. The choice of psychotropic treatment should be based on creatinine, transaminases values, albumin levels in plasma and concomitant treatment. Due to potential side effects such as obesity, diabetes, immunosuppression, careful selection of atypical antipsychotics in the treatment of psychotic symptoms and monitoring of relevant indicators is necessary [36]. It should be noted that in the treatment of corticosteroid-induced depression, tricyclic antidepressants can cause exacerbation of symptoms with manifestations of auditory and visual hallucinations [37]. Sertraline and escitalopram are an appropriate choice as they do not enter into clinically significant drug interactions, as opposed to fluoxetine and paroxetine [32]. Some authors suggest treatment of corticosteroid-induced psychoses with lithium or valproate [38, 39]. Lithium, however, is not suitable in patients with rheumatic diseases affecting renal function due to renal excretion and narrow therapeutic window [32].

\section{Case 1}

The patient is a 29-year-old woman, unmarried, with a University degree in economics, working in marketing. Born of a normal second pregnancy. No mental illness in the family. In October 2017, she complained of high fever, sore throat, headache, limb pain. Laboratory tests were performed, and leukocytosis was established. She was consulted with a haematologist and diagnosed with acute myeloid leukaemia in November. Initially, chemotherapy was performed, and her brother turned out to be an appropriate donor, and in February 2018, allogeneic bone marrow transplantation was performed. The next step in the treatment was oral administration of prednisolone with an initial daily dose of $100 \mathrm{mg}$. Each week the prednisolone dose was reduced by $10 \mathrm{mg}$. Upon reaching a dose of $50 \mathrm{mg}$ daily, the patient suddenly changed her behaviour. She became psychomotor agitated and disorganized. She was in an elevated mood with ecstatic and megalomaniac experiences, "phenomenal abilities to predict the future, to manage time and space," with a shortened duration of night sleep. Nevertheless, temporal, spatial and personality orientation remained intact. Her condition required hospitalization at the Oncohematology Clinic and consultation with a psychiatrist. Upon our recommendation, prednisolone treatment was discontinued, and treatment with olanzapine was initiated at doses of $10 \mathrm{mg} /$ day and diazepam $10 \mathrm{mg} /$ night. Within 3 days the described psychopathological symptoms were reduced and at the end of the stay de-actualized, as a result of which the antipsychotic was discontinued according to a schedule.

\section{Case 2}

The patient is a 55-year-old family woman, with 2 children, with high school education, working as a healthcare professional. In 2015 she had been diagnosed with two autoimmune diseases: Raynaud syndrome and Sjogren's syndrome. Due to elevated transaminase levels, she was admitted to the gastroenterology clinic in October 2017 and diagnosed with autoimmune hepatitis. 
Treatment with methylprednisolone was initiated with an initial dose of $40 \mathrm{mg} /$ day, equivalent to $50 \mathrm{mg}$ prednisolone. During inpatient treatment, she became internally very tense, often cried, felt depressed and tired, had no strength and energy. She began accusing herself of all family misfortunes that she was born without luck. Night sleep was disturbed. She was consulted with a psychiatrist about the described anxiety-depressive symptomatology and subsequently hospitalized in a psychiatric clinic in November 2017 with a moderately severe depressive episode. Given the accompanying autoimmune hepatitis, treatment with milnacipran $100 \mathrm{mg} / \mathrm{d}$ and pregabalin 150 $\mathrm{mg} / \mathrm{d}$ (drugs without hepatic metabolism) was performed. The appearance of maculopapular rash on the skin of the whole body required a reduction in the dose of methylprednisolone to $4 \mathrm{mg} / \mathrm{d}$. Within one month, improvement in sleep and mood was reported. It was recommended to continue treatment with milnacipran at a supporting dose of $100 \mathrm{mg}$ /day. In 2018 the patient was admitted twice for inpatient treatment with acute anxiety-depressive symptoms after self-induced antidepressant withdrawal. She was carrying out supportive treatment of accompanying autoimmune diseases with methylprednisolone at $4 \mathrm{mg} / \mathrm{d}$. In the meantime, she also experienced a series of psycho traumatic family-related situations (lack of support and understanding on the part of her husband) and subsequent fourth diagnosis of autoimmune thyroiditis.

\section{DISCUSSION}

In the first case, the acutely-manifested manic-paranoid symptoms were de-actualized by discontinuing prednisolone, which emphasizes the possible role of the corticosteroid for its occurrence, although the manifestation was at half of the initial dose, i.e. at $50 \mathrm{mg} / \mathrm{d}$, during the fifth week of treatment. The psychopathological symptomatology required olanzapine to be administered for a short period of time. This case supports some authors' claims that there is no relationship between dosage and treatment duration on the severity of symptoms and their occurrence [26].

In the second case, the causes of depression were complex. The administered methylprednisolone at a dose of $30 \mathrm{mg} / \mathrm{d}$ (equivalent to $50 \mathrm{mg}$ prednisolone) could be considered as a trigger for the onset of anxiety-depressive symptoms, although the incidence of psychiatric disorders at doses below $40 \mathrm{mg} / \mathrm{d}$ is low $(1.3 \%)$, and they manifest in long-term treatment with corticosteroids [20]. On the other hand, the high incidence $(50 \%)$ of depression among patients with autoimmune diseases should be considered [40]. Autoimmune thyroiditis itself implies manifestation of a clinical picture of depression [41]. Depression-inducing factors include polymorbidity, psycho traumatic factors and lack of supportive family environment.

\section{CONCLUSION:}

Corticosteroids have a high potential to induce a wide range of mental disorders presenting with symptoms of depression, anxiety, mania, delirium and schizophrenia. They occur regardless of administration route and are not associated with past psychiatric disorders or a family burden. Although there is no specific recommendation dedicated to the prevention of psychiatric complications, clinicians should be aware of these adverse side effects. The awareness of physicians, patients and families are crucial for their recognition and timely treatment.

The most common psychiatric disorders observed during short-term corticosteroid therapy are euphoria and hypomania, while long-term treatment primarily induces symptoms of depression. This necessitates a precise assessment of the risk factors and the use of safe doses of this class of drugs as their manifestations are dose-dependent. Risk groups prone to corticosteroid-induced psychosis are children and adults over 65 years of age. The inability to stop corticosteroid treatment requires the use of psychotropic medications. Both drug interactions and potential side effects need to be considered.

\section{REFERENCES:}

1. Paragliola RM, Papi G, [PubMed] [Crossref] Pontecorvi A, Corsello SM. Treatment with Synthetic Glucocorticoids and the Hypothalamus-Pituitary-Adrenal Axis. Int J Mol Sci. 2017 Oct 20;18(10) pii:E:2201. [PubMed] [Crosref]

2. Knezevic NN, Voronov D, Candido KD. The efficacy and safety of corticosteroids in the treatment of acute and chronic pain. SJAIT 2016; 38(5-6):129-136. [Crossref]

3. Schiff D, Lee EQ, Nayak L, Norden AD, Reardon DA, Wen PY. Medical management of brain tumors and the sequelae of treatment. Neuro Oncol. 2015 Apr;17(4):488-504.
4. Yasir M, Sonthalia S. Corticosteroid Adverse Effects. StatPearls [Internet]. Treasure Island (FL): StatPearls Publishing; 2019 Mar 24. [PubMed]

5. Kusljic S, Manias E, Gogos A. Corticosteroid-induced psychiatric disturbances: It is time for pharmacists to take notice. Res Social Adm Pharm. 2016 Mar-Apr;12(2):355-60. [PubMed] [Crossref]

6. Wolkowitz OM, Rubinow D, Doran AR, Breier A, Berrettini WH, Kling MA. Prednisone effects on neurochemistry and behavior. Preliminary findings. Arch Gen Psychiatry.1990; 47(10):963-968. [Crossref]

7. Herman JP, McKlveen JM, Ghosal S, Kopp B, Wulsin A, Makinson $\mathrm{R}$, et al. Regulation of the Hypothalamic-Pituitary-Adrenocortical Stress Response. Compr Physiol. 2016 Mar 15;6(2):603-21. [PubMed] Crossref]

8. Carroll BJ, Iranmanesh A, Keenan DM, Cassidy F, Wilson WH, Veldhuis JD. Pathophysiology of hypercortisolism in depression: pituitary and adrenal responses to low glucocorticoid feedback. Acta Psychiatr Scand. 2011 Jun;125(6):478-91. [PubMed] [Crossref] 
9. Brown WA, Johnston R, Mayfield D. The 24-hour dexamethasone suppression test in a clinical setting: Relationship to diagnosis, symptoms, and response to treatment. Am J Psychiatry. 1979 Apr;136(4B):543-7. [PubMed]

10. Lotrich FE. Inflammatory cytokine-associated depression. Brain Res. 2015 Aug 18;1617:113-25. [PubMed] [Crossref]

11. Arnaudova-Zhekova MD. [Introduction to advanced and late-age psychiatry.] University Publishing House of Medical University - Varna. 2015. p. 175-216. [in Bulgarian]

12. Achkova. [Psychiatry.] Znanie Î̂D. 1996. p. 90-97. [in Bulgarian]

13. Conner SH, Solomon SS. Psychiatric Manifestations of Endocrine Disorders. J Hum Endocrinol. 2017; 2:1-7. [Crossref]

14. Ward L, George J. Corticosteroid-induced psychosis in rheumatoid arthritis. Progress in Neurology and Psychiatry. 2016 Sept/Oct;20(5):1315. [Crossref]

15. Ou G, Bressler B, Galorport G, Lam E, Ko HH, Enns R, et al. Rate of Corticosteroid-Induced Mood Changes in Patients with Inflammatory Bowel Disease: A Prospective Study. JCAG. 2018 Sep;1(3):99-106. [PubMed] [Crossref]

16. Fardet L, Petersen I, Nazareth I. Suicidal behavior and severe neuropsychiatric disorders following glucocorticoid therapy in primary care. Am J Psychiatry. 2012 May; 169(5):491-7. [PubMed] [Crossref]

17. Ciriaco M, Ventrice P, Russo G, Scicchitano M, Mazzitello G, Scicchitano F, Russo E. Corticosteroid-related central nervous system side effects. $J$ Pharmacol Pharmacother. 2013 Dec; 4(Suppl 1): S94-8. [PubMed] [Crossref]

18. Manzo C, Serra-Mestres J, Castagna A, Isetta M. Behavioral, Psychiatric, and Cognitive Adverse Events in Older Persons Treated with Glucocorticoids. Medicines (Basel). 2018 Aug 1;5(3)pii:E82. [PubMed] [Crossref]

19. Swinburn CR, Wakefield JM, Newman SP, Jones PW. Evidence of prednisolone induced mood change ('steroid euphoria') in patients with chronic obstructive airways disease. $\mathrm{Br}$ J Clin Pharmacol 1988 Dec; 26(6):

\section{9-13. [PubMed] [Crossref]}

20. Acute adverse reactions to prednisone in relation to dosage. Clin Pharmacol Ther. 1972 Sep-Oct; 13(5):694-8. [PubMed] [Crossref]

21. Lewis DA, Smith RE. Steroidinduced psychiatric syndromes. A report of 14 cases and a review of the literature J Affect Disord. 1983 Nov; 5(4):319-32. [PubMed] [Crossref]

22. Warrington TO, Bostwick JM. Psychiatric adverse effect of corticosteroids. Mayo Clin Proc. 2006 Oct; 81(10):1361-7. [PubMed] [Crossref]

23. Hall R, Popkin M, Stickney S, Gardner ER. Presentation of the steroid psychoses. J Nerv Ment Dis. 1979 Apr;167(4):229-36. [PubMed] [Crossref]

24. Fardet L, Nazareth I, Whitaker HJ, Petersen I. Severe neuropsychiatric outcomes following discontinuation of long-term glucocorticoid therapy: a cohort study. J Clin Psychiatry. 2013 Apr;74(4):e281-6. [PubMed] [Crossref ]

25. Turner P. Clinical pharmacology in criminal cases: discussion paper. J R Soc Med. 1987 Jul;80(7):43840. [PubMed] [Crossref]

26. Ling MH, Perry PJ, Tsuang MT. Side effects of corticosteroid therapy. Psychiatric aspects. Arch Gen Psychiatry. 1981 Apr;38(4):471-7. [PubMed] [Crossref]

27. Bolanos SH, Khan DA, Hanczyc M, Bauer MS, Dhanani N, Brown ES. Assessment of mood states in patients receiving long-term corticosteroid therapy and in controls with patientrated and clinician-rated scales. Ann Allergy Asthma Immunol. 2004 May; 92(5):500-5. [PubMed] [Crossref]

28. George ME, Sharma V, Jacobson J, Simon S, Nopper AJ. Adverse Effects of Systemic Glucocorticosteroid Therapy in Infants With Hemangiomas. Arch Dermatol. 2004 Aug;140(8):9639. [PubMed] [Crossref]

29. Benyamin RM, Vallejo R, Kramer J, Rafeyan R. Corticosteroid induced psychosis in the pain management setting. Pain Physician. 2008 Nov-Dec;11(6):917-20. [PubMed]

30. Robinson DE, HarrisonHansley E, Spencer RF. Steroid psychosis after an intra-articular injection. Ann Rheum Dis. 2000 Nov;
59(11):927. [PubMed] [Crossref]

31. Liu EY, Vasudev A. Mania induced by clarithromycin in a geriatric patient taking low-dose prednisone. Prim Care Companion CNS Disord. 2014;16(3). pii: PCC.14101626. [PubMed] [Crossref]

32. Tenev V. Drug Interaction Guide in Psychiatry and General Practice. Iztok - Zapad EAD; 2008. p.109128.

33. Chau SY, Mok CC. Factors predictive of corticosteroid psychosis in patients with systemic lupus erythematosus. Neurology. 2003 Jul 8; 61(1):104-7. [PubMed] [Crossref]

34. International Classification of Diseases X revision. Bulgarian Psychiatric Association; 2008. p. 57-61.

35. Wada K, Yamada N, Sato T, Suzuki H, Miki M, Lee Y, Akiyama K, Kuroda S. Corticosteroidinduced psychotic and mood disorders: Diagnosis defined by DSM-IV and clinical pictures. Psychosomatics. 2001 NovDec;42:461-6. [PubMed] [Crossref]

36. Stroup TS, Gray N. Management of common adverse effects of antipsychotic medications. World Psychiatry. 2018 Oct;17(3):341-356. [PubMed] [Crossref]

37. Dietch JT. Steroid psychosis and tricyclic antidepressants. Arch Gen Psychiatry. 1982 Feb;39(2):236. [Crossref]

38. Roxanas MG, Hunt GE. Rapid reversal of corticosteroid-induced mania with sodium valproate: a case series of 20 patients. Psychosomatics. 2012 Nov-Dec;53(6):575-81. [PubMed] [Crossref]

39. Falk WE, Mahnke MW, Poskanzer DC. Lithium prophylaxis of corticotropin-induced psychosis. JAMA. 1979 Mar 9;241(10):1011-2. [PubMed] [Crossref]

40. Pryce CR, Fontana A. Depression in Autoimmune Diseases. Curr Top Behav Neurosci. 2017; 31:139154. [PubMed] [Crossref]

41. Siegmann E, Muller HHO, Luecke C, Philipsen A, Kornhuber J, Gromer TW. Association of Depression and Anxiety Disorders With Autoimmune Thyroiditis: A Systematic Review and Meta-analysis. JAMA Psychiatry. 2018; 75(6):577-584. [PubMed] [Crosref] 
Please cite this article as: Telbizova T, Arnaoudova M. Corticosteroids - (Un)predictable inducers of psychiatric disorders. J of IMAB. 2019 Oct-Dec;25(4):2775-2780. DOI: https://doi.org/10.5272/jimab.2019254.2775

Received: 21/05/2019; Published online: 11/11/2019

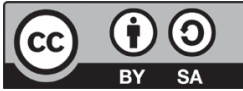

Address for correspondence:

Tatyana Telbizova, MD,

Department of psychiatry and medical psychology, Medical University-Varna, MHAT "St. Marina”,

1, Hristo Smirnenski str., 9010Varna, Bulgaria

Tel.: +359877028456

E-mail: ttelbizova@gmail.com 